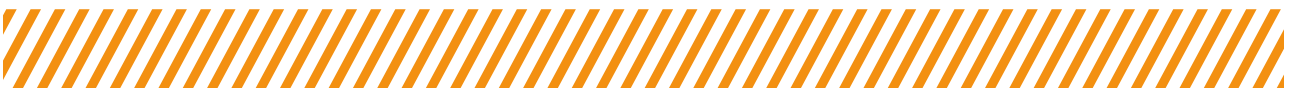

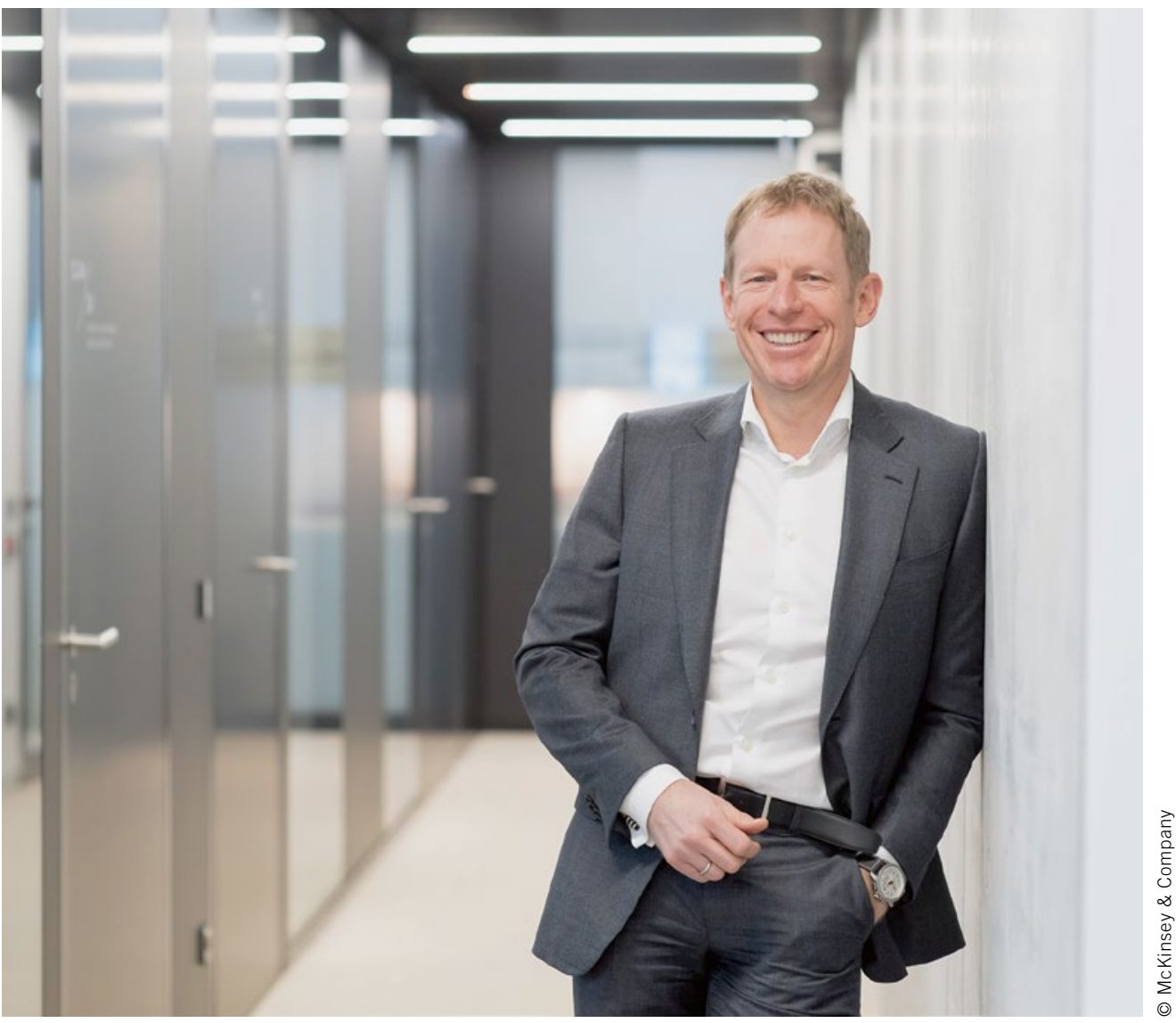

Andreas Tschiesner

Senior Partner at the Munich office of the management consulting firm McKinsey \& Company and Director of European Automotive Consulting

\section{Preparing for the World after Corona}

The Covid-19 pandemic represents a major challenge for the automotive industry. In addition to swift and determined responses to the sudden crisis, the protection of lives and health of people, and the securing of financial resources, companies need to develop an appropriate long-term strategy. Indeed, success in the long run will depend on a long-term strategy that takes account of five stages: resolve; resilience; return; re-imagination; and reform. Nearly all of the big players in the automotive industry have successfully completed the first stage of crisis management by demonstrating resolve. Moreover, lessons learned from past downturns offer valuable guidance when it comes to crisis resilience. Companies that have a healthy bottom line going into a downturn, that retain their capacity to make fundamental decisions, and that maintain organic sales growth tend to manage crises better than others. A return to pre-crisis production activities, however, is sometimes more difficult than suspending production activities. The task of resuscitating supply chains requires a structured approach. Given the complexity of today's global supply chains, coordinated approaches to ramping up production are crucial. The Coronavirus pandemic will force us to reimagine the way we live, work and use technology. So it is no surprise that many enterprises are attempting to initiate or accelerate structural changes, whether these efforts come in the form of go-to-market strategies, cooperations and alliances, novel work-design projects, alternative geographic orientations, or cost shifting.

The Covid-19 crisis can also be expected to have a longterm impact on mobility. The development of the new "normal" will be one of the most important challenges in any successful long-term strategy. The associated need for reform will be reflected in the future mix of mobility solutions we find in our cities, in new business models ratified in company boardrooms and in horizontal cooperation strategies. Adapting cost structures to the new normal will also be essential. For more than 100 years, the automotive industry has been a driving force for economic and societal advancement. The five-stage approach can help companies in the automotive sector and other industries to survive the current pandemic and to recover quickly once it is over. 